\section{Conflicts of interest in genetic counseling: persistent underlying questions}

To the Editor: We appreciate Iacoboni and colleagues'l letter as a welcome continuation of the conversation that we hoped to promote. Iacoboni et al. also mention the work of the Task Force on conflicts of interest (COI), recently commissioned by the National Society of Genetic Counselors; these resources, made available after our commentary was submitted, are another welcome addition to this much-needed conversation.

Iacoboni et al., who are all employed by Invitae Corporation, describe their laboratory's efforts to mitigate COI among their genetic counselors (GCs) - including multiple points of disclosure and a noncommissioned salary structure-which we wholeheartedly applaud. In our view, it is unfortunate that, in the absence of industry regulation or accountability on this issue, patients cannot be assured that all laboratories make similar efforts.

It is worthwhile to reiterate that we do not believe that laboratory-employed GCs are unable to provide quality patient care. As we emphasized in our commentary, "We recognize that genetic counselors employed by laboratories are likely no less focused on providing the best, professionally responsive care than any other genetic counselor." ${ }^{2}$ This observation, however, does not negate the simple fact of COI for GCs who are simultaneously beholden to the National Society of Genetic Counselors' Code of Ethics, which calls for GCs to enable patient decision making with balanced information about options and alternatives, and to a commercial employer whose existence depends on maintaining or increasing test sales.

As the Institute of Medicine defines it, the concept of COI pertains to the situation (i.e., working for a corporate entity while simultaneously providing care), not to the actions taken. COI do not necessarily mean that a clinician does or will compromise his or her duties to patients, and are certainly not prima facie evidence of unethical behavior. COI are an important professional issue for the entire genetic counseling profession, and our discussion of the topic is in no way a personal attack on the competence or capabilities of GCs working in commercial laboratories.

We also agree that further empirical research on this issue and its real and potential consequences is important, and appreciate Iacoboni and colleagues' recent work in beginning to fill this evidence gap. However, the most important question, from our perspective, is not whether laboratoryemployed GCs provide quality patient care.

We believe a larger issue at stake is the usage of laboratoryemployed GCs within the marketing plans of commercial genetic testing laboratories, whose undisputed primary interest is to increase genetic test sales. The availability of posttest genetic interpretation by a certified GC is undoubtedly a plus for laboratories seeking to expand their clinician networks and market share. And commercial laboratories have consistently pushed to market their tests beyond current professional recommendations. In only one recent example, the chief executive officer of Counsyl characterized the company's goals as "making expanded carrier screening as routine as taking folic acid, noninvasive prenatal screening as routine as an ultrasound, and hereditary cancer screening as well-known as a pap smear."3 The conflicts that arise from these GC-laboratory relationships are likely to become even more complex as laboratories expand their test offerings to include bigger panels, and even wholeexome sequencing aimed at the healthy population, in order to maximize testing volume.

Finally, as Iacoboni et al. point out, we are in a time of provider scarcity; however, the model of laboratory-employed GCs providing patient-facing services does not solve this problem. On the contrary, the shortage of providers qualified to provide clinical genetic counseling is being created in part by commercial testing laboratories, who are generating new markets through programs that promote expansive genetic testing to people who do not have a medical or family history indication for testing. One such example is Invitae's new "proactive" Genetic Health Screen. ${ }^{4}$ While we are glad to see that consultation with a GC is available for these patients, this model shifts resources away from those who have identified indications for services within health care institutions. The innovative delivery models mentioned by Iacoboni et al., including telehealth, are equally effective when used by nonlaboratory-employed GCs, who may deliver care through provider or insurance networks or through contractual arrangements with clinician groups.

As we noted in our original commentary, genetic counseling is a young profession-and one in which patients, who may have only a single encounter on which to judge, can easily lose trust. Disclosure and mitigation of COI can help maintain public trust and institutional trustworthiness, if implemented transparently with accountability. The potential policy solutions we suggested did include possible limits on patientfacing genetic counseling by laboratory-employed GCs, but more importantly they focused on a publicly accessible database of COI disclosures and a broad slate of mitigation strategies for both laboratories and health-care institutions. We still believe that genetic counseling, as a profession, needs to continue this difficult but important conversation, and to work toward cooperative and responsible solutions.

\section{DISCLOSURE}

The authors declare no conflict of interest. Dr. Michie is supported by $\mathrm{NIH}$ grant ROOHG006452. 
Katie A. Stoll, MS, CGC $C^{1}$, Amanda Mackison, $M P P^{1}$, Megan A. Allyse, $P h D^{2}$ and Marsha Michie, $P h D^{3}$

${ }^{1}$ Genetic Support Foundation, Olympia, Washington, USA; ${ }^{2}$ Biomedical Ethics Program, Mayo Clinic, Rochester, Minnesota, USA; ${ }^{3}$ Institute for Health \& Aging, University of California, San Francisco, San Francisco, California, USA

Correspondence: Marsha Michie (marsha.michie@ucsf.edu)

\section{REFERENCES}

1. Iacoboni D, Lynch K, Esplin ED, Nussbaum RL. Conflicts of interest in genetic counseling: addressing and delivering. Genet Med 2018;20. E-pub ahead of print 4 January 2018.
2. Stoll KA, Mackison A, Allyse MA, Michie M. Conflicts of interest in genetic counseling: acknowledging and accepting. Genet Med 2017;19: 864-866.

3. Counsyl Celebrates 10 Year Anniversary With New Financing and New Board Member. 6 November 2017. https://blog.counsyl.com/2017/11/06/ counsyl-celebrates-10-year-anniversary-with-new-financing-and-newboard-member/. Accessed 13 November 2017.

4. Invitae Expands Test Menu for Proactive Genetic Testing in Healthy Adults. 23 March 2017. https://www.invitae.com/en/press/invitae-expands-testmenu-proactive-genetic-testing/. Accessed 13 November 2017.

Advance online publication 4 January 2018. doi:10.1038/gim.2017.235 